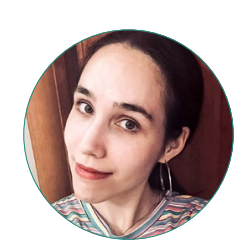

О.Р. Михайлова

\title{
ВОЗМОЖНОСТИ ПРИМЕНЕНИЯ ЭГО-СЕТЕВОГО АНАЛИЗА ДЛЯ ИЗУЧЕНИЯ РАСПРОСТРАНЕНИЯ МОРАЛЬНОЙ ПАНИКИ НА МЕЖИНДИВИДУАЛЬНОМ УРОВНЕ
}

\section{Правильная ссылка на статью:}

Михайлова О.Р. Возможности применения эго-сетевого анализа для изучения распространения моральной паники на межиндивидуальном уровне // Мониторинг общественного мнения: экономические и социальные перемены. 2021. № 2. С. 28-47. https:// doi.org/10.14515/monitoring.2021.2.1818.

\section{For citation:}

Mikhaylova O. R. (2021) The Perspectives of Ego-Network Analysis in the Moral Panic Propagation Studies on the Interpersonal Level. Monitoring of Public Opinion: Economic and Social Changes. No. 2. P. 28-47. https://doi.org/10.14515/monitoring.2021.2.1818. (In Russ.) 
ВОЗМОЖНОСТИ ПРИМЕНЕНИЯ ЭГОСЕТЕВОГО АНАЛИЗА ДЛЯ ИЗУЧЕНИЯ РАСПРОСТРАНЕНИЯ МОРАЛЬНОЙ ПАНИКИ НА МЕЖИНДИВИДУАЛЬНОМ УPOBHE

МИХАЙЛОВА Оксана Рудольфовна аспирантка аспирантской школы по социологическим наукам, стажер-исследователь Центра исследований современного детства, Национальный исследовательский университет "Высшая школа экономики", Москва, Россия E-MAIL: oxanamikhailova@gmail.com https://orcid.org/0000-0002-0236-6992

Аннотация. Моральная паника возникает в результате веры в существование людей, поведение которых якобы не согласуется с текущими моральными нормами и тем самым угрожает сохранности социума. Будучи предложенным С. Коэном в конце XX века, это понятие не нашло устойчивого места в лексиконе социальных наук, в том числе из-за трудностей его операционализации и последующего измерения.

В статье мы обсуждаем перспективы, открываемые перед исследованиями моральной паники эго-сетевым анализом. Мы опираемся на определение данного понятия через веру в современную легенду и используем социально-психологический подход к его изучению. На примере моральной паники относительно ожирения мы подробно анализируем методические решения, которые требуется принять при сборе и анализе данных с использованием эго-сетей в рамках биографических интервью. В заключение делаются выводы относительно преимуществ, которыми обладает предложенная в статье методология, и обсуждаются
THE PERSPECTIVES OF EGO-NETWORK ANALYSIS IN THE MORAL PANIC PROPAGATION STUDIES ON THE INTERPERSONAL LEVEL

Oxana R. MIKHAYLOVA ${ }^{1}-P h$. D. student (Sociology); Research Assistant at the Centre for Modern Childhood Studies E-MAIL: oxanamikhailova@gmail.com https://orcid.org/0000-0002-0236-6992

\footnotetext{
${ }^{1}$ National Research University Higher School of Economics, Moscow, Russia
}

Abstract. Moral panic is a collective reaction that stems from a belief in the existence of people whose behavior contradicts social expectations and therefore threatens societal safety. This concept, while being proposed by Stanley Cohen at the end of the 20th century, has not yet gained a stable position in the social sciences lexicon due to the difficulties of its operationalization and subsequent evaluation.

The paper discusses the perspectives of ego-network analysis for moral panic studies. The author relies on the definition of this concept through belief in a contemporary legend and uses a socio-psychological approach to its analysis. Basing on the example of moral panic about obesity, the author studies the methodological decisions that should be made when collecting and analyzing data using ego-networks in the framework of biographical interviews. In conclusion, the author discusses advantages of the approach proposed in the paper and names methodological and theoretical issues, that need to be addressed for this methodology to be applied in empirical research. 
методические и теоретические вопросы, решение которых необходимо для ее полноценного использования.

Ключевые слова: моральная паника, современная легенда, эго-сети, сетевой анализ, глубинное интервью, ожирение, межиндивидуальный уровень

Благодарность. Автор выражает благодарность Быкову Андрею Вячеславовичу за комментарии и советы при подготовке статьи, которые поспособствовали повышению ее качества.
Keywords: moral panic, contemporary legend, ego-networks, social network analysis, in-depth interview, obesity, interpersonal level

Acknowledgments. The author expresses gratitude to Andrey V. Bykov for his comments and suggestions which helped to improve the quality of this paper.

В последнее время исследователи фиксируют повышение уровня тревожности на индивидуальном и групповом уровнях в связи с различными социальноэкономическими стрессорами (такими как пандемия коронавируса, которая внесла существенный вклад в ухудшение психологического благополучия детей и взрослых по всему миру [Salari et al., 2020]). В статье мы обращаемся к изучению механизмов распространения такого коллективного феномена, как моральная паника (МП), возникающего вследствие тревог, испытываемых на групповом уровне [Garland, 2008], и делаем это на примере МП относительно ожирения.

Моральная паника - это результат веры в современную легенду. В свою очередь, современная легенда - это нарратив о том, что существует субъект (группа субъектов, "народные дьяволы"), поведение которого не соответствует текущим моральным нормам и угрожает сохранности общества [Victor, 1998]. Не все типы современных легенд могут вызывать МП: в основу МП ложатся только те из них, что имеют негативный, в некоторых случаях даже стигматизирующий характер. Легенды же, заключающие в себе шутливый нарратив, где не упоминается нанесение серьезного вреда героям, обычно не побуждают массовых страхов и тревог и, скорее, выполняют функцию развлекательной истории, которую рассказывают собеседнику для поддержания непринужденной беседы.

Определяя МП через веру в современную легенду, мы сознательно опускаем дискуссию относительно дефиниций МП, поскольку наша работа имеет методический фокус. Однако исследователи ставят целый ряд вопросов относительно данного концепта. В частности, в литературе по теме обсуждаются трудности операционализации этого понятия, ценностная окрашенность и необходимость ограничения круга эмпирических явлений, к которым оно применяется [David et al., 2011; Михайлова, 2020].

Вклад в распространение МП вносят различные типы акторов: СМИ, «моральные предприниматели" ${ }^{1}$, социальные движения, сами "народные дьяволы", го-

1 Под "моральными предпринимателями" понимаются люди, осознанно и целенаправленно распространяющие современную легенду в рамках МП. Например, активисты, которые верят в то, что Билл Гейтс создал коронавирус, чтобы массово чипировать мировое население, повреждают вышки 5G, считая, что они распространяют коронавирус. 
сударство, а также аудитория (публика). Важно оговорить, что данный феномен не является простой суммой сходных индивидуальных эмоциональных состояний, действий, а представляет собой совместное действие [Walby, Spencer, 2011]. То есть МП - это результат конвергенции индивидуальных актов, поэтому изучать его следует с использованием не только психологической, но и социологической оптики.

Современная легенда распространяется в форме слухов, требований, обвинений и предложений относительно того, как необходимо поступить с народными дьяволами. Например, в рамках МП относительно ожирения циркулирует информация о том, что полные люди, будучи виноватыми в своей полноте по причине "нездорового" образа жизни, создают серьезную нагрузку на систему здравоохранения страны, а также становятся обузой для своих родственников и знакомых [Murray, 2008]. Кроме того, они формируют неправильные ориентиры для детей и молодежи, нормализуя наличие лишнего веса. В связи с этим, согласно МП, таких людей необходимо лечить, приводить в форму и всячески способствовать тому, чтобы они похудели и пришли к "нормальному" весу, иначе общество будет продолжать нести издержки, связанные с обеспечением их жизни.

Исследователи рассматривают МП в связи с широким кругом вопросов, касающихся как центральной для этого понятия проблематики (детей и молодежи), так и новых сюжетов (животные, технологические риски, здоровье) [Cohen, 2011; Михайлова, 2020]. Несмотря на динамичное развитие данной научной области, одним из проблемных вопросов остается недостаточность внимания, уделяемого роли аудитории в распространении МП [David et al., 2011]. СМИ не только выступают в качестве первостепенного источника интереса для социальных исследователей, помимо этого аудитория изучается преимущественно лишь с опорой на данные СМИ. Такая стратегия изучения аудитории может давать некорректную информацию о механике явления, что, в свою очередь, мешает предсказанию тенденций его развития. В связи с этим возникает необходимость в разработке способов исследования диффузии МП на микроуровне от "человека к человеку". В данной статье мы предлагаем подход, который позволит решить обозначенную проблему. Мы хотим рассмотреть возможности применения эго-сетевого анализа для измерения распространения этого феномена на межиндивидуальном уровне. Эго-сетевой анализ - это техника сбора и анализа персональных связей человека, которая используется в качественных и количественных исследованиях, а также в исследованиях, выполненных смешанными методами. Она уже применялась для анализа распространения различных социальных представлений - например, идеологий/дискурсов/установок [Bernhard, 2018], однако ее возможности для анализа диффузии МП еще не отрефлексированы.

Стратегию измерения распространения МП на межиндивидуальном уровне мы обсуждаем на примере МП относительно ожирения. Последнее рассматривается некоторыми исследователями как социально сконструированная проблема [Monaghan, Hollands, Prtichard, 2010]. В производстве этой проблемы считаются задействованными СМИ, государство, научное сообщество, специалисты, занимающиеся общественным здоровьем, и люди, которые на индивидуальном уровне выстраивают свою жизнь в соответствии с представлением о существовании 
такого феномена, как ожирение. Мы предполагаем, что предметом изучения среди всех акторов МП относительно ожирения при помощи качественных эго-сетевых интервью могут стать индивиды, имплементирующие диетические практики в собственную жизнь. Эти “моральные паникеры" воспроизводят современную легенду об ожирении ${ }^{2}$.

Итак, цель статьи состоит в разработке методологии для изучения распространения МП на межиндивидуальном уровне. Такая методология, как мы надеемся, сделает извлечение информации о восприятии аудиторией паники более валидным и поможет расширить знания исследователей о механизмах диффузии данного явления на межиндивидуальном уровне. Также наша работа раскрывает новую область применения эго-сетевого анализа. Использование эго-сетевого анализа в исследованиях МП, вероятно, создает специфику реализации этой техники, ее более глубокая рефлексия, на наш взгляд, возможна в последующих эмпирических исследованиях.

Далее мы продемонстрируем существующие методические стратегии для анализа динамики МП и теоретические предпосылки применения эго-сетевого анализа для изучения данного явления. После этого подробно представим процедуру интервью с использованием эго-сетевого анализа и те методические выборы, которые возникают перед желающими внедрить эту технику в свой исследовательский проект. В заключении мы обобщим возможности и преимущества представленной в статье методологии, а также предложим направления для дальнейших исследований.

\section{Методические стратегии измерения динамики моральной паники}

Исследование динамики МП является одним из теоретических объектов изучения в данной научной области наряду с «моральными предпринимателями", "народными дьяволами", СМИ, социальной культурой контроля, публикой. Динамика МП в большей мере рассматривается в ходе социально-исторических исследований [Deflem, 2019] и анализа СМИ [Мейлахс, 2004; Алексеев, 2017; Ефанов, 2018; Саляхиева, Савельева, 2018]. С измерением динамики распространения МП напрямую связан анализ восприимчивости публики к содержанию современной легенды, который обычно проводится с помощью фокус-групп [Pearce, Charman, 2011], экспериментов [Johnen, Jungblut, Ziegele, 2018], опросов [Schildkraut, Elsass, Stafford, 2015] и этнографии [Flores-Yeffal, Vidales, Martinez, 2019]. Несмотря на то, что перечисленные стратегии решают проблему измерения аудитории МП и позволяют оценить восприятие людьми современной легенды, они обладают двумя значимыми недостатками:

1) не позволяют напрямую изучить процесс включения человека в МП;

2) не учитывают влияние социального окружения и его различных сетевых характеристик на восприятие человеком современной легенды.

\footnotetext{
2 Мы называем их моральными паникерами, а не моральными предпринимателями, поскольку имеем в виду не только тех людей, кто распространяет МП осознанно, но и тех, кто делает это неосознанно, так как воспроизводит знания/осуществляет практики, свойственные тем, кто верит в современную легенду, лежащую в ядре МП. Таким образом, наше понятие морального паникера включает в себя моральных предпринимателей, а также некоторых представителей публики, распространяющих легенду нецеленаправленно.
} 
В рамках эксперимента тестируется гипотеза идентификации с современной легендой [Johnen, Jungblut, Ziegele, 2018], а в случае фокус-групп для людей создается неестественная ситуация ознакомления с современной легендой и включения в МП [Pearce, Charman, 2011]. Таким образом, в обеих стратегиях анализ распространения МП на межиндивидуальном уровне происходит в искусственно созданной обстановке, что может сказаться на экологической валидности результатов, получаемых по результатам подобных исследований. В тех же работах (oпросах [Schildkraut, Elsass, Stafford, 2015], этнографических исследованиях [Flores-Yeffal, Vidales, Martinez, 2019]), где вера в современную легенду измеряется у людей, имеющих к ней отношение, и не создается искусственно, усвоение легенды рассматривается индивидуализированно, то есть не принимается в расчет влияние социального окружения человека, который воспринимает современную легенду, на его отношение к этой легенде (о том, как окружение может влиять на усвоение человеком тех или иных установок, пойдет речь в следующей части статьи). В то же время исследований распространения МП немного, поэтому мы до конца не понимаем, как МП передается от человека к человеку и переходит с макроуровня на микроуровень ${ }^{3}$.

Понимая два основных недостатка имеющихся стратегий измерений МП, мы предлагаем методическую стратегию измерения распространения МП, которая позволяет справиться с ними. Наше предложение заключается в применении эго-сетевого анализа в качественных биографических интервью ${ }^{4}$. Мы полагаем, что в ходе подобных интервью станет возможным повышение экологической валидности исследований распространения МП, поскольку диффузия анализируется на основе данных, полученных от людей, уже включенных в МП в прошлом или находящихся в ней сейчас. Также такие интервью позволят выяснить, как окружение человека связано с его индивидуальной динамикой веры в современную легенду, чего не позволяли сделать описанные экспериментальные исследования и фокус-группы. Наряду с этим посредством интервью можно определить роль СМИ и моральных предпринимателей в распространении МП. К тому же анализ данных, собранных вышеописанными методами, может производиться не только качественным образом. Это создает предпосылки для построения причинно-следственных связей и прогнозирования. Связи информантов и их степень веры в современную легенду могут быть изучены с применением количественного анализа текстов и сетевого анализа. Для увеличения надежности данных лучше комбинировать сбор информации через интервьюирование с анализом личных документов, таких как дневники, и изучением репрезентаций "народных дьяволов" в СМИ. Далее подробнее остановимся на теоретических предпосылках предлагаемого подхода для измерения распространения МП на межиндивидуальном уровне.

\footnotetext{
з Здесь мы специально уточняем, что в данной статье идет речь именно об измерении МП в современном мире, поскольку в прошлом распространение коллективных эмоциональных реакций происходило несколько иным образом [Дмитриев, Сычев, 2014]. До развития современных форм СМИ МП распространялись без их участия. Примером подобного рода МП, которые существовали до современных моральных паник, служит "охота на ведьм".

4 Подробнее о теоретических и методологических основаниях биографического метода в социологии можно прочесть в книге «Биографический метод в социологии» [Рождественская, 2012].
} 


\section{Теоретические основания измерения динамики распространения моральной паники на межиндивидуальном уровне \\ с использованием эго-сетевого анализа и биографических интервью}

В основе нашего представления о том, что современная легенда, вера в которую инициирует начало МП, может передаваться через непосредственные социальные связи, а не только при помощи СМИ, "моральных предпринимателей" и культуры контроля, лежит социально-психологический подход к изучению МП [Pearce, Charman, 2011]. В рамках этого подхода в исследовательском фокусе находится роль публики в распространении МП. Социальные психологи [ibidem] отмечают недостаточность внимания, уделяемого восприятию публикой данного феномена, в работах, написанных после появления диссертации С. Коэна (одного из авторов теории МП). В его диссертации реакция аудитории изучалась посредством групповых дискуссий и индивидуальных интервью. В вышедших позже работах анализ СМИ редко совмещается с изучением публики, из-за чего восприятие этим агентом паники остается в тени.

Вместе с тем причины, которые лежат за присоединением к МП, неоднозначны: нельзя сказать, что эти паники привлекают больше внимания аудитории, если они апеллируют к эмоциям или направлены на работу с человеком через убеждение, риторические приемы (когнитивный уровень) [Critcher, Pearce, 2013]. Среди сюжетов МП есть те, которые привлекают больше эмоциональной реакции (иммиграция, педофилия, уличные кражи), и те, к которым относятся менее эмоционально (рекреационное потребление психоактивных веществ, секс и насилие в СМИ). Также социальные психологи считают, что объяснить отклик на МП можно процессами групповой динамики. Соответственно, для того чтобы выяснить, почему человек присоединился к панике, необходимо изучить отношения между его группой и группой “народных дьяволов". Как правило, МП позволяет укрепить социальную идентичность обеих групп (паникеров и "народных дьяволов"), поскольку создается позитивный образ ингруппы и контрастный, зачастую негативный - аутгруппы. В свою очередь, причины обращения морального паникера к материалам из СМИ предлагается объяснять теорией социальных репрезентаций С. Московичи [Московичи, 1995]. Социальные репрезентации, которые производят СМИ, входят в обиход морального паникера, поскольку помогают лучше ориентироваться в границах своей группы.

Социально-психологическое объяснение формирования МП использовалось в небольшом количестве эмпирических исследований. Работа Дж. Пирс и Э. Чарман показала, что люди, включенные в МП относительно иммигрантов, действительно опираются на репрезентации иммигрантов в СМИ и имеют слабое представление о реалиях жизни этих «народных дьяволов" [Pearce, Charman, 2011]. Эксперимент, проведенный для анализа факторов, способствующих участию в онлайн-МП, продемонстрировал, что субъективное представление о сходстве с людьми, которые уже затронуты паникой, способствует включению в нее [Johnen, Jungblut, Ziegele, 2018].

Дополнить социально-психологическую рамку объяснения МП, на наш взгляд, может сетевой анализ, поскольку в нем существует несколько обоснований (гипотез) того, почему человек оказывается в окружении людей, по тем или иным атрибутам похожих на него (социальное влияние, социальный отбор, коэволюция). 
Соответственно, эти обоснования потенциально могут помочь в объяснении того, как связаны окружение человека и степень его веры в современную легенду.

Гипотеза социального влияния основана на предположении, что когда между двумя людьми завязываются социальные отношения, со временем, в процессе взаимодействия, они становятся более похожими друг на друга [Friedkin, 2001]. Применительно к изучению МП это означает, что степень веры человека в современную легенду может измениться в результате коммуникации с другими людьми. То есть можно стать частью сообщества морально паникующих людей, изначально не веря в современную легенду, войдя в контакт с одним из них и переняв его установки и практики в ходе взаимодействия.

Гипотеза социального отбора (социальной селекции), в свою очередь, исходит из того, что существуют социальные процессы, влияющие на способность актора сформировать связь [Lazarsfeld, Merton, 1954]. Один из таких процессов - гомофилия (тенденция к формированию связей с похожими на тебя индивидами). Основываясь на теории социального отбора, можно предположить, что люди склонны формировать социальные отношения с теми, кто обладает одинаковой степенью веры в современную легенду. Иными словами, маловероятно стать членом сообщества моральных паникеров, если у тебя нет склонности к вере в легенду или ты в нее уже не веришь.

Коэволюционный подход - это третий тип объяснения связи между личностными установками, практиками и социальными контактами [Lazer, 2001]. В рамках этого подхода утверждается, что люди склонны искать баланс между собственными и чужими установками и практиками. Такой баланс может быть установлен несколькими путями:

1) при помощи образования связей с похожими на эго альтерами ${ }^{5}$;

2) адаптации эго к группе;

3) путем комбинации 1 и 2 способов балансировки.

То есть из коэволюционного подхода следует, что человек, который имеет склонность к вере или уже верит в современную легенду, может быть предрасположен к включению в сообщество людей, имеющих с ним близкую степень веры. В то же время индивид может адаптировать свою веру к среднегрупповой с течением времени, чтобы лучше интегрироваться в выбранную им социальную группу.

Таким образом, социально-психологический подход к объяснению МП предполагает, что персональные связи могут иметь значение для распространения современной легенды, поскольку люди со схожими опасениями способны формировать группу и укреплять свою идентичность посредством конструирования образа аутгруппы. Распространение современной легенды среди подобных людей может объясняться одним или несколькими из описанных выше сетевых обоснований диффузии установок и поведенческих характеристик. Далее мы опишем процедуру проведения интервью с эго-сетевым анализом, посредством которой можно проверить подобное теоретическое объяснение распространения МП. Проиллюстрируем эту процедуру вопросами, измеряющими МП относительно ожирения.

\footnotetext{
5 Под альтерами в сетевых исследованиях обычно понимаются другие люди/организации/животные и иные субъекты и объекты, с которыми эго строит связи. В данной статье мы в первую очередь называем альтерами людей, входящих в социальное окружение информанта.
} 


\section{Процедура измерения распространения моральной паники на межиндивидуальном уровне посредством биографических интервью и эго-сетевого анализа}

Эго-сетевой анализ - это техника сбора и анализа социальных связей человека. Мы предлагаем использовать ее именно в качественном интервью для изучения участников МП, поскольку применение эго-сетевого анализа в нем позволит получить более подробное описание характера связей, которые формирует моральный паникер. Нам необходимо добиться как можно более подробного описания отношений информанта с другими людьми, так как фиксация источников получения информации о современной легенде в рамках формализованного интервьюирования может привести к искаженному представлению о порядке ее распространения.

Например, если в рамках опроса мы узнаем, что об опасности ожирения и методах борьбы с лишним весом человек первый раз услышал от своей подруги, то это может привести нас к выводу, что на установки по отношению к своему телу первоначально повлияла подруга респондента. В свою очередь, дополнительные вопросы в процессе неструктурированного качественного интервью могут показать, что подруга получила эти знания об ожирении не от своих знакомых, а читая информацию в онлайн-сообществах, посвященных похудению. Таким образом, наше предположение о том, что установки относительно ожирения распространяются посредством межличностной коммуникации, сделанное на основе результатов опроса, окажется не совсем точным. Конечно, в целях стандартизации и удешевления процедуры исследования можно перевести ее в опросную форму, но лучше пытаться делать это только после проведения серии разведочных исследований, которые позволят сформировать предположения о процессе распространения той или иной МП на межиндивидуальном уровне. Эго-сетевой анализ обладает гибкостью в реализации, поэтому далее, помимо общей структуры качественного интервью с применением эго-сетевого анализа, мы подробно опишем исследовательские выборы и их достоинства и недостатки, с которыми сталкивается тот, кто решает использовать эту технику в своей работе.

Мы не будем подробно останавливаться на этом моменте, но до сбора эго-сети информанта необходимо расспросить о его степени веры в современную легенду или выявить ее косвенными методами, например, при помощи анализа личных документов. Далее следует перейти к сбору эго-сетевых данных. Мы считаем, что интервьюирование должно начинаться с выяснения установок информанта по отношению к современной легенде, потому что это в дальнейшем может помочь участнику исследования оценить степень веры в нее альтеров и связи их веры с установками и практиками эго.

\section{Сбор эго-сетевых данных в качественном интервью}

Как правило, процедура интервью с использованием эго-сетей начинается с расспроса человека об именах людей, входящих в его социальное окружение (альтеров). Затем исследователи выясняют характеристики альтеров, например, их роли, социально-демографические данные. Далее с информантом обсуждают связи, которые есть между людьми из его окружения. В заключение рисуется 
карта окружения информанта и проверяется корректность зафиксированных в ходе интервью связей между эго и его альтерами.

При планировании порядка проведения интервью, если исследователь хочет использовать картирование, необходимо также решить, в какой момент оно будет происходить и кто будет рисовать сеть (интервьюер или информант). Картирование эго-сети может осуществляться до, во время или после интервью. В зависимости от того, в какой момент интервью производится графическое отображение связей информанта, можно получить более или менее расширенные нарративы от участника интервью. Так, предъявление информанту сети в начале интервью, структурированной исследователем на основе нереактивных данных, может привести к искажению всего дальнейшего процесса интервью, поскольку человек будет опираться не на свою логику упорядочивания связей, а на предложенную ему интервьюером.

Не менее значим и выбор субъекта, картирующего связи информанта. От этого зависит агентность данных, которые будут получены в результате исследования. Так же, как и в случае с предъявлением информанту заранее подготовленной карты, интервьюер способен повлиять на логику структурирования связей информантом. Однако иногда все же имеет смысл отдать картирование на откуп интервьюеру, приняв во внимание риски искажения. Если рисовать сеть будет интервьюер, то это позволит ускорить процесс интервьюирования, стандартизировать его, а также поможет при работе с людьми с низким уровнем образования / детьми / информантами с ментальными и физическими особенностями. Например, в ходе интервьюирования людей с деменцией исследователи отмечают необходимость большей вовлеченности интервьюера в проведение беседы, даже выработки дополнительных "поддерживающих" техник ведения разговора [Галкин, 2020].

Наряду с принятием решения о процессе проведения картирования нужно определиться с тем, будет ли ограничиваться количество альтеров, о которых может рассказать информант в ходе интервью. Ограничение количества альтеров, с одной стороны, ведет к ускорению, удешевлению и стандартизации процедуры. С другой стороны, лимитирование человека по количеству альтеров приводит к получению неполной информации о его/ее сети. Далее остановимся подробнее на этапах интервьюирования.

\section{Выявление людей, входящих в социальное окружение информанта}

Расспрашивание информанта о людях, входящих в его окружение, обычно составляет первый этап сбора эго-сетевых данных. Оно представляет собой вопрос или серию вопросов, направленных на выявление социальных контактов человека (например, “Назовите, пожалуйста, имена тех людей, с которыми Вы обсуждаете похудение»).

На этой стадии интервью необходимо определиться с типом и количеством вопросов, которые будут задаваться для выяснения связей человека. В зависимости от типа вопросов, которые спрашиваются у информантов, исследователи получают разные по размерам и степени детализации сети, здесь мы опишем три основных типа вопросов, выделяемых К. Бидарт и Дж. Шарбоне [Bidart, Charbonneau, 2011], а также те виды данных, которые можно получить, пользуясь ими. 
Вопросы, позволяющие построить сеть на основе данных о регулярности взаимодействия эго и альтеров. В рамках интервью вопрос такого типа может выглядеть следующим образом: «Подумайте, пожалуйста, о всех людях, с которыми Вы взаимодействуете (например, по телефону, в социальных сетях, в мессенджерах, офлайн), и назовите тех из них, с кем Вы наиболее часто обсуждаете похудение». Такой тип вопросов направлен на получение информации о тех, с кем информант поддерживает отношения на регулярной основе. Он исходит из предположения, что социальное благополучие индивида связано с размером сети, в которую он включен, и частотой контактов с этими людьми [ibid.: 270-272]. Обычно этот тип вопросов используется в исследованиях социальной изоляции индивидов и применяется не только в рамках интервьюирования. Нередко данные о взаимодействиях человека получают от сотовых операторов, провайдеров интернета и т. д. Главный недостаток подобного типа генератора имен - игнорирование людей, с которыми информант редко поддерживает контакты: альтер может быть весьма значимым для эго, несмотря на невысокую частоту контактов с ним. Кроме того, исследования показывают, что социальная изоляция не напрямую связана с размером сети контактов человека, скорее, играет роль субъективная оценка степени собственной изолированности.

Вопросы, позволяющие построить сеть на основе данных о субъективной степени значимости альтеров для эго. Вопрос, соответствующий данному типу в интервью, может выглядеть следующим образом: «Назовите, пожалуйста, имена тех людей, с которыми в последние шесть месяцев Вы обсуждали наиболее значимые для Вас вопросы в сфере похудения". В основе этого типа вопросов лежит задача выяснения наиболее значимых для человека альтеров. Традиция использования таких вопросов зародилась в антропологии и городских исследованиях [ibid.: 272-273]. Основным недостатком такого способа выяснения социального окружения человека является многозначность самого слова «значимость". Как правило, информанты по-своему понимают его, в результате каждый выдает список людей, основанный на собственных представлениях о значимости людей. Вдобавок часто информанты забывают озвучить имена людей, с которыми у них есть негативные связи, то есть тех, кто с их точки зрения мешал, создавал трудности для них.

Для решения проблемы полисемии вопросы, направленные на выявление значимых для человека социальных контактов, советуют операционализировать в виде «батареи», разделенной на отдельные тематические блоки. В нашем случае, отдельно спрашивают у участника исследования о людях, которые были значимы для внедрения в образ жизни ограничительных практик в питании, физических нагрузок, представлений о необходимости корректировки тела и т. д. Искажения, вносимые в данные в связи с неупоминанием в ходе интервью информантом негативных для человека альтеров, могут быть решены путем дополнительных инструкций в процессе интервью. Например, "Скажите, пожалуйста, а был ли кто-то в Вашем окружении, кто скептически отнесся к Вашему желанию начать худеть?".

Вопросы, позволяющие построить сеть на основе данных об обменах, которые осуществляет эго. Такие вопросы в рамках интервью могут носить проспективный или ретроспективный характер. Проспективный вопрос: “Если бы Вам понадоби- 
лось получить информацию о похудении, к кому бы Вы обратились с этой просьбой?». Ретроспективный вопрос: “Когда Вы хотели узнать, какой образ жизни необходимо вести для похудения, к кому Вы обращались за советом?". Приведенный тип вопросов был разработан в исследованиях социального капитала, где он использовался для изучения социальной поддержки, которой располагает индивид [ibid.: 273-275]. Чаще всего подобный способ сбора связей эго критикуется с точки зрения аутентичности ситуации, в которую помещают информанта. В этом случае возможность обмена / получения помощи сильно зависит от обстоятельств. Кроме того, считается, что этот способ сбора эго-сетевых данных позволяет измерить только сеть социальной поддержки человека, но не способствует получению информацию обо всем его окружении.

Несмотря на то, что каждый из перечисленных способов формирования списка социальных контактов человека обладает определенными недостатками, есть и общая критика, относящаяся к выяснению социальных связей человека посредством интервьюирования его в рамках опроса или качественного интервью. Она касается надежности (риск получения данных с когнитивными искажениями), специфичности (информанты склонны вспоминать только наиболее сильные связи, теряется информация о более слабых связях эго), обобщаемости результатов (неизвестно, упоминает ли информант все связи, которыми он/она обладает в ходе интервью) и цены (интервью занимает несколько часов) [Hogan, Carrasco, Wellman, 2007]. Решение всех этих вопросов - насущная задача для современных методических исследований в области сетевого анализа. Иногда на этой же стадии интервью, после создания списка людей, входящих в окружение информанта одним из перечисленных выше способов или их комбинацией, сгенерированные имена наносятся на карту.

\section{Выяснение характеристик людей, входящих в социальное окружение информанта}

После того, как исследователь составил список альтеров информанта, происходит интерпретация названных имен посредством уточнения социальнодемографической информации о названных альтерах и других параметров, значимых для исследователя: “Расскажите, пожалуйста, поподробнее о Саше...” Например, можно спросить о возрасте, поле, частоте контактов с эго, продолжительности знакомства с ним, а также о профессиональной деятельности альтера [Cullingham, 2013].

Кроме того, интервьюируя информанта о его социальном окружении, мы хотим узнать, как связано это окружение с его/ее верой в современную легенду. Соответственно, на этом этапе нужно уточнить степень веры альтеров морального паникера в современную легенду. Измерение этой степени можно осуществить с помощью батареи-воронки вопросов. То есть начать интервьюирование с отношения к социальной проблеме в целом и таким образом выявить общее содержание современной легенды: "Скажите, пожалуйста, а Саша тоже считает значимой проблему ожирения для России?". Затем следует уточнить, как повседневная жизнь альтера соотносится с этой верой. Например, в случае МП, касающейся ожирения, конкретизировать телесные практики альтеров и их отношение к пол- 
ным людям: “А как, с Вашей точки зрения, Саша относится к людям „в теле“?”; “Что Саша делает, чтобы держать себя в форме?".

\section{Построение матрицы связей между эго и альтерами}

После того как интервьюер получил информацию об альтерах, нужно уточнить связи между альтерами: "Скажите, пожалуйста, а Саша и Лера знакомы между собой?». Можно зафиксировать данные об отношениях между альтерами в виде матрицы либо записать эту информацию в свободной форме. При составлении матрицы связей уточняются отношения между альтерами и эго. Информантов просят рассказать, как, по их мнению, складываются отношения между парами альтеров. На этом этапе исследователю необходимо определиться со способом фиксации наличия связи; выбрав один из критериев: субъективно (в связи с представлениями информанта) или объективно (с опорой на дефиницию, данную исследователем). Субъективное определение наличия связи, с одной стороны, способно обогатить данные исследования смыслами, которые человек вкладывает в понятие связи, с другой стороны, такой подход к фиксации связей усложнит сопоставление кейсов между собой.

\section{Картирование социального окружения информанта}

Некоторые аспекты применения картирования уже были затронуты в начале этой статьи, теперь остановимся на нем подробнее. Исследователи, которые проводят интервью с применением эго-сетевого анализа, используют разные рисуночные техники. Эти техники были разработаны в нескольких дисциплинах, поэтому их эффективность в немалой степени зависит от соответствия исследовательскому вопросу. В целом считается, что рисование эго-сети позитивно сказывается на исходе исследовательского процесса. В частности, визуализация эго-сети в качественном интервью:

1) улучшает качество данных (работает как дополнительный способ стимуляции памяти информанта);

2) облегчает коммуникацию интервьюера и информанта;

3) позволяет информанту абстрагироваться и увидеть свое социальное окружение со стороны;

4) может быть способом предоставления обратной связи;

5) дает дополнительные аналитические возможности (полезна для анализа структуры, выделения групп, типологий, моделей, сравнения эго-сетей во времени) [Molina, Maya-Jariego, McCarty, 2014].

Картирование может быть свободным или делаться с учетом заданной исследователями структуры. Наиболее известный структурированный метод картирования - иерархическое картирование американских психологов Р. Кана и Т. Антонуччи [Kahn, Antonucchi, 1980]. Эта рисуночная техника разработана в психологии развития. Авторы техники выделяют три уровня близости (теоретические и эмпирические), поэтому иерархическое картирование предполагает использование трех концентрических кругов для отображения персональных контактов человека [Molina, Maya-Jariego, McCarty, 2014]. В середине схемы находится слово “Вы”, и информантов просят расположить людей, с которыми 
они взаимодействуют, на расстоянии от центра круга в зависимости от степени близости отношений, которые информант имеет с тем или иным человеком. Эта техника позволяет понять примерный размер сети и ее распределение с точки зрения близости к респонденту.

Альтернативой структурированным способам картирования выступает свободный дизайн. Исследования демонстрируют, что он подходит для информантов с высоким экономическим статусом, при более низком экономическом статусе применяют структурированные техники [Hollstein, Töpfer, Pfeffer, 2020]. В то же время было выявлено, что информанты предпочитают концентрические круги Р. Кана и Т. Антонуччи свободному дизайну и воронкам. Помимо учета предпочтений информанта при выборе типа техники нужно ориентироваться на исследовательскую задачу.

Кроме того, при разработке стратегии картирования необходимо выбрать между бумажным и электронным сбором информации. Как показало исследование Б. Хогана, Дж. Карраско и Б. Велмана, бумажное картирование дает возможность получения более качественных данных. Также оно надежнее, чем электронное. Помимо этого, в процессе рисования эго-сетей на бумаге люди чувствуют себя включеннее в процесс. Эта процедура пока дешевле электронной и предоставляет дополнительные аналитические возможности [Hogan, Carrasco, Wellman, 2007]. Вместе с тем бумажное картирование требует бо́льших вложений в тренинг интервьюеров, подготовку и сбор оборудования, нежели электронное. Вдобавок нужно много места для размещения полотна, на котором происходит рисование. K тому же эффект интервьюера в процессе бумажного картирования больше, чем при электронном сборе информации. Для того чтобы его уменьшить, Б. Хоган, Дж. Карраско и Б. Велман советуют исследователям разработать как можно более детализированные рекомендации для интервьюеров по процедуре картирования.

\section{Анализ данных качественного эго-сетевого интервью}

По результатам сбора данных при помощи качественных эго-сетевых интервью исследователь получает два типа данных (сетевые и нарративные). В научной литературе предлагаются разные способы их анализа. Поскольку в нашем интервью помимо вопросов об эго-сетях выясняется степень веры в МП, то необходимо также разработать стратегию анализа информации, полученной о данном предмете изучения. Это отдельная исследовательская задача, которой мы не будем касаться в данной статье. При анализе данных о социальном окружении, полученных посредством качественных эго-сетевых интервью, следует определиться с соотношением изучения сетевых данных и нарративных: будет ли отдан приоритет информации, полученной исходя из построения эго-сети, нарративных данных, или в равной степени будут учтены оба источника данных.

В первом случае, если делается выбор в пользу анализа эго-сети, а нарративные данные второстепенны, то изучаются структура и композиция полученных эго-сетей [Molina, Maya-Jariego, McCarty, 2014]. Также могут исследоваться группы альтеров, которые выделил сам информант или исследователь на основе характеристик альтеров и их связей, полученных от информанта. Нарративы, в свою очередь, используются как вспомогательный источник информации. Применение 
такого подхода может быть удобным для ускорения процедуры анализа, а также стандартизации. Однако в таком случае исследователь теряет смысловую палитру, которую формирует при рассказе о своем окружении информант. В результате ускользает из виду то, как человек рассказывает о своих связях, что в случае сенситивных тем исследования, которые нередко связаны с МП, может обеднить исследовательские выводы.

Во втором случае эго-сеть выступает как инструмент сбора текстовых данных и не анализируется. Поэтому после получения нужных данных аналитик сосредотачивается на текстовых данных, интерпретируя их, исходя из выбранного подхода к анализу текстов [Noack, Schmidt, 2013]. Отказ от анализа эго-сетей может быть связан с необходимостью приобретения дополнительных компетенций для анализа сетевых данных (освоения методов и программ). Вместе с тем, ограничиваясь только интерпретацией текста, исследователь лишается возможности для построения количественных моделей ${ }^{6}$, позволяющих статистически доказать релевантность одного из конкурирующих между собой объяснений распространения МП в сетевом анализе (социальное влияние, социальный отбор, коэволюция). Кроме того, без анализа сетевых данных количественными методами затруднены прогнозы распространения измеряемой МП в будущем.

В третьем случае предлагается одновременно анализировать эго-сети и текстовые данные, описывающие содержание этих сетей. Например, в рамках качественного структурного анализа, в котором скомбинированы принципы сетевого структурного анализа и качественного нарративного анализа данных, процедура анализа включает три этапа [Altissimo, 2016]. Сначала исследователи изучают карту без обращения к нарративу. По результатам анализа карты формулируются предположения о структуре и композиции сети информанта. Затем следует анализ нарратива из интервью, в рамках которого тоже делаются выводы об альтерах эго. В заключение сопоставляются результаты анализа карты и нарратива. После этого результаты, полученные по итогам анализа двух типов материалов, совмещаются и создается резюме кейса.

Поскольку однозначных аргументов в пользу того или иного подхода к анализу данных интервью с применением эго-сетей пока нет, мы предполагаем, что выбор подхода должен зависеть от временнб́х ресурсов, которыми обладает исследователь, поскольку построение эго-сетей требует не только знакомства с соответствующими программами анализа сетевых данных, но и значительного количества времени. Во-вторых, поскольку карта сети человека и его рассказ предоставляют возможности для триангуляции данных, более выигрышна будет комбинация данных в ходе аналитической процедуры, как предлагается в третьем подходе к анализу качественных эго-сетевых данных.

\section{Заключение}

Мы рассмотрели возможности, открывающиеся в результате применения эгосетевого анализа для исследований распространения МП на межиндивидуальном уровне, руководствуясь определением МП через современную легенду, а также

\footnotetext{
6 Подробнее об основных лонгитюдных моделях в сетевом анализе можно прочитать в [Snijders, 2005; Докука, Валеева, 2015].
} 
иллюстрируя их на примере МП относительно ожирения. Было продемонстрировано, что использование эго-сетей в биографических интервью помогает решить две основные проблемы существующих методических стратегий анализа распространения МП.

Во-первых, предлагаемая нами методическая стратегия подразумевает выяснение истории включения в МП и позволяет напрямую изучить процесс включения человека в этот феномен, а следовательно, выяснить факторы, которые в прошлом способствовали формированию текущей степени веры морального паникера в современную легенду.

Во-вторых, сбор и анализ данных о социальном окружении морального паникера в динамике потенциально может способствовать восполнению наших знаний о том, как социальное окружение таких людей связано со степенью их веры в современную легенду. Эти знания могут формироваться как из качественного анализа данных нарративов, так и из количественной оценки эго-сетей, получаемых по результатам интервьюирования. Кроме того, в случае использования на этапе анализа данных количественных методов лонгитюдного сетевого моделирования становится возможным осуществление прогнозов относительно будущих установок, а также предсказания характеристик окружения человека, способствующих его/ее включению в МП. Такая информация может быть использована не только в исследовательских целях, но и для превенции развития МП. Возможно, что в дальнейшем, используя эго-сети, мы выясним, что в зависимости от типа паники действуют различные механизмы распространения современной легенды. Помимо этого, может быть выявлена степень значимости персональных контактов для распространения разных типов паник. Мы предполагаем, что эгосетевой анализ также может потенциально ответить на вопрос, почему разные по способам воздействия на аудиторию паники распространяются с соизмеримой скоростью и приобретают сопоставимые масштабы.

Обсуждая применение эго-сетей в биографических интервью для анализа распространения МП, мы также осветили методические выборы, которые необходимо осуществить в процессе подготовки исследования. Эти выборы касаются характера вопросов, задаваемых для определения лиц, входящих в социальное окружение паникера, использования картирования эго-сетей в процессе сбора и анализа данных. Однако мы не останавливались на операционализации степени веры в современную легенду, блок вопросов о которой также должен содержаться в подобном интервью. Этот аспект требует дальнейших исследований, чтобы сформировать полноценный инструментарий для анализа распространения МП на межиндивидуальном уровне.

\section{Список литературы (References)}

Алексеев А. Б. Конструирование моральной паники в политическом дискурсе //Политическая лингвистика. 2017. № 2. С. 55-64.

Alekseev A. B. (2017) Moral Panic in Political Discourse. Political Linguistics. No. 2. P. 55-64. (In Russ.) 
Галкин К. Особенности нерационального социологического интервью: если у информанта диагноз "деменция" // Laboratorium: журнал социальных исследований. 2020. Т. 12. № 2. С. 212-220. https://www.doi.org/10.25285/2078-19382020-12-2-212-220.

Galkin K. (2020) Features of an "Irrational" Sociological Interview: If the Informant Is Diagnosed with Dementia. Laboratorium: Russian Review of Social Research. Vol. 2. No. 12. P. 212-220. https://www.doi.org/10.25285/2078-1938-2020-12-2-212220. (In Russ.)

Дмитриев А., Сычев А. Скандал. Социофилософские очерки. 2014. М. : ЦСП и М. Dmitriev A., Sychev A. (2014) Scandal. Sociophilosophical Essays. Moscow: TsSP and M. (In Russ.)

Докука С. В., Валеева Д. Р. Статистические модели для анализа динамики социальных сетей в исследованиях образования // Вопросы образования. 2015. № 1. C. 201-213. https://www.doi.org/10.17323/1814-9545-2015-1-201-213.

Dokuka S. V., Valeeva D.R. (2015) Statistical Models for Analysis of Social Network Dynamics in Educational Studies. Educational Studies. No. 1. P. 201-213. https:// www.doi.org/10.17323/1814-9545-2015-1-201-213. (In Russ.)

Ефанов А. А. “Волны” моральных паник в российском обществе 1990-2010-х годов: историко-социологический анализ // Известия Саратовского Университета. Новая Серия. Серия: Социология. Политология. 2018. Т. 18. № 1. С. 4-9. https:// www.doi.org/10.18500/1818-9601-2018-18-1-4-9.

Efanov A. A. (2018) “Waves" of Moral Panics in Russian Society in 1990-2010s: Historical-Sociological Analysis. Izvestia of Saratov University. New Series. Series: Sociology. Politology. Vol. 18. No. 1. P. 4-9. https://www.doi.org/10.18500/18189601-2018-18-1-4-9. (In Russ.)

Мейлахс П.А. Дискурс прессы и пресс дискурса: конструирование проблемы наркотиков в петербургских СМИ // Журнал социологии и социальной антропологии. 2004. T. 7. № 4. C. $135-151$.

Meilakhs P.A. (2004) Press Discourse and Pressing of the Discourse: Construction of the Drug Problem in St. Petersburg Mass Media. Journal of Sociology and Social Anthropology. Vol. 4. No. 7. P. 135-151. (In Russ.)

Михайлова О.Р. Кто использует понятие моральной паники? Библиометрический анализ научных публикаций. Социологическое обозрение. 2020. Т. 19. № 19. C. 351-375.

Mikhaylova O.P. (2020) Who Uses the Moral Panic Concept? A Bibliometric Analysis of Moral Panic Scientific Literature. The Russian Sociological Review. Vol. 19. No. 3. P. 351-375. (In Russ.)

Московичи С. Социальные представления: исторический взгляд. Психологический журнал. 1995. Т. 16. № 1. С. 3-18.

Moscovici S. (1995) Social Representations: A Historical View. Psychological Journal. Vol. 1. No. 16. P. 3-18. (In Russ.) 
Рождественская Е. Ю. Биографический метод в социологии. М. : Изд. дом Высшей школы экономики, 2012.

Rozhdestvenskaya E. Yu. (2012) Biographical Method in Sociology. Moscow: The Higher School of Economics Publishing House. (In Russ.)

Саляхиева Л. М., Савельева Ж. В. Добровольная бездетность в российском обществе и медиа: конструирование социальной проблемы чайлдфри // Научный Татарстан. 2018. № 4. С. 46-61.

Salyakhieva L. M., Savelyeva J.V. (2018) Voluntary Childlessness in Russian Society and Media: Construction of Childfree's Social Problem. Scientific Tatarstan. No. 4. P. 46-61. (In Russ.)

Altissimo A. (2016) Combining Egocentric Network Maps and Narratives: An Applied Analysis of Qualitative Network Map Interviews. Sociological Research Online. Vol. 21. No. 2. P. 152-164. https://doi.org/10.5153/sro.3847.

Bernhard S. (2018) Analyzing Meaning-Making in Network Ties - A Qualitative Approach. International Journal of Qualitative Methods. December. https://doi.org/10.1177/ 1609406918787103.

Bidart C., Charbonneau J. (2011) How to Generate Personal Networks: Issues and Tools for a Sociological Perspective. Field Methods. Vol. 23. No. 3. P. 266-286. https:// doi.org/10.1177/1525822X11408513.

Cohen S. (2011) Folk Devils and Moral Panics. London: Routledge.

Critcher C., Pearce J. (2013) A Missing Dimension: The Social Psychology of Moral Panics. In: Krinsky Ch. (ed.) The Ashgate Research Companion to Moral Panics. P. 371-386. Farnham: Ashgate Publishing.

Cullingham C. M. (2013) New Mothers' Networks in the Canadian Context: A Combined Methods Investigation into the Characteristics, Function, and Dynamics of First Time Mothers' Social Networks (Unpublished master's thesis). Calgary: University of Calgary. https://doi.org/10.11575/PRISM/27096.

David M., Rohloff A., Petley J., Hughes J. (2011) The Idea of Moral Panic - Ten Dimensions of Dispute. Crime, Media, Culture: An International Journal. Vol. 7. No. 3. P. 215-228. https://doi.org/10.1177/1741659011417601.

Deflem M. (2019) Popular Culture and Social Control: The Moral Panic on Music Labeling. American Journal of Criminal Justice. No. 45. P. 2-24. https://doi.org/10.1007/ s12103-019-09495-3.

Flores-Yeffal N. Y., Vidales G., Martinez G. (2019) \#WakeUpAmerica, \#IIlegalsAreCriminals: The Role of the Cyber Public Sphere in the Perpetuation of the Latino Cyber-Moral Panic in the US. Information, Communication \& Society. Vol. 22. No. 3. P. 402-419. https:// doi.org/10.1080/1369118X.2017.1388428.

Friedkin N.E. (2001) Norm Formation in Social Influence Networks. Social Networks. Vol. 3. No. 23. P. 167-189. https://doi.org/10.1016/S 0378-8733(01)00036-3. 
Garland D. (2008) On the Concept of Moral Panic. Crime, Media, Culture: An International Journal. Vol. 4. No. 1. P. 9-30. https://doi.org/10.1177/1741659007087270.

Hogan B., Carrasco J. A., Wellman B. (2007) Visualizing Personal Networks: Working With Participant-Aided Sociograms. Field Methods. Vol. 19. No. 2. P. 116-144. https:// doi.org/10.1177/1525822X06298589.

Hollstein B., Töpfer T., Pfeffer J. (2020) Collecting Egocentric Network Data With Visual Tools: A Comparative Study. Network Science. Vol. 8. No. 2. P. 223-250. https:// doi.org/10.1017/nws.2020.4.

Johnen M., Jungblut M., Ziegele M. (2018) The Digital Outcry: What Incites Participation Behavior in an Online Firestorm? New Media \& Society. Vol. 20. No. 9. P. 3140-3160. https://doi.org/10.1177/1461444817741883.

Kahn R. L., Antonucci T. C. (1980) Convoys Over the Life Course: Attachment Roles and Social Support. In: Baltes P. B., Brim O. G. (eds.) Life-Span Development and Behavior. Vol. 3. P. 253-286. New York: Academic Press.

Lazarsfeld P. F., Merton R. K. (1954) Friendship as a Social Process: A Substantive and Methodological Analysis. Freedom and Control in Modern Society. P. 18-66.

Lazer D. (2001) The Co-Evolution of Individual and Network. Journal of Mathematical Sociology. Vol. 25. No. 1. P. 69-108. https://doi.org/10.1080/002225 OX.2001.9990245.

Molina J. L., Maya-Jariego I., McCarty C. (2014) Giving Meaning to Social Networks: Methodology for Conducting and Analyzing Interviews Based on Personal Network Visualizations. In: Mixed Methods Social Networks Research. Design and Applications. P. 305-335. Cambridge: Cambridge University Press.

Monaghan L., Hollands R., Prtichard G. (2010) Obesity Epidemic Entrepreneurs: Types, Practices and Interests. Body \& Society. Vol. 16. No. 2. P. 37-71. https://doi.org/ $10.1177 / 1357034 \times 10364769$.

Murray S. (2008) Pathologizing “Fatness": Medical Authority and Popular Culture. Sociology of Sport Journal. Vol. 25. No. 1. P. 7-21. https://doi.org/10.1123/ssj.25.1.7.

Noack A., Schmidt T. (2013) Narrating Networks: A Narrative Approach of Relational Data Collection. Procedia - Social and Behavioral Sciences. Vol. 100. P. 80-93. https://doi.org/10.1016/j.sbspro.2013.10.701.

Pearce J. M., Charman E. (2011) A Social Psychological Approach to Understanding Moral Panic. Crime, Media, Culture: An International Journal. Vol. 7. No. 3. P. 293-311. https://doi.org/10.1177/1741659011417607.

Salari N., Hosseinian-Far A., Jalali R., Vaisi-Raygani A., Rasoulpoor Sh., Mohammadi M., Rasoulpoor Sh., Khaledi-Paveh B. (2020) Prevalence of Stress, Anxiety, Depression Among the General Population During the COVID-19 Pandemic: A Systematic Review and Meta-Analysis. Globalization and Health. Vol. 16. No. 57. https://doi.org/10.1186/ s12992-020-00589-w. 
Schildkraut J., Elsass H. J., Stafford M. C. (2015) Could It Happen Here? Moral Panic, School Shootings, and Fear of Crime Among College Students. Crime, Law and Social Change. Vol. 63. P. 91-110. https://doi.org/10.1007/s10611-015-9552-z.

Snijders T. A. (2005) Models for Longitudinal Network Data. In: Models and Methods in Social Network Analysis. P. 215-247. New York: Cambridge University Press.

Victor J.S. (1998) Moral Panics and the Social Construction of Deviant Behavior: A Theory and Application to the Case of Ritual Child Abuse. Sociological Perspectives. Vol. 41. No. 3. P. 541-565. https://doi.org/10.2307/1389563.

Walby K., Spencer D. (2011) How Emotions Matter to Moral Panics. In: Hier S. (ed.) Moral Panic and the Politics of Anxiety. London: Routledge. P. 117-130. 